\title{
PRODUTIVIDADE EM PESQUISA DO CNPq: ANÁLISE DO PERFIL DOS PESQUISADORES DA QUÍMICA
}

\author{
Natacha Carvalho Ferreira Santos*\#, Lucilene Faustina de Oliveira Cândido e Cristiano Lima Kuppens \\ Conselho Nacional de Desenvolvimento Científico e Tecnológico, SEPN 509, Bl. A - Ed. Nazir I, 70750-501 Brasília - DF, Brasil
}

Recebido em 10/11/09; aceito em 18/12/09; publicado na web em 2/2/10

\begin{abstract}
RESEARCH PRODUCTIVITY OF CNPq: ANALYSIS OF THE CHEMISTRY RESEARCHERS' PROFILE. The profile of the CNPq Research Productivity Program in Chemistry was studied using the Plataforma Lattes curricula of all researchers with grants in effect as of March 2009. Most of them are male (67.2\%), working in Federal Universities (59.4\%) and located in Southeastern Brazil $(63.7 \%)$. There is no evident homogeneity among researchers of the same level/category concerning the productivity criterions used (the $\mathrm{H}$ index and the scientific productivity of the last five years). CNPq and the Chemistry Assessor Committee have been focusing on making their judgments unbiased, by using quantitative parameters, but such overlap is still noticeable.
\end{abstract}

Keywords: Chemistry; bibliometric indexes; research productivity.

\section{INTRODUÇÃO}

A bolsa de produtividade em pesquisa (PQ) do Conselho Nacional de Desenvolvimento Científico e Tecnológico (CNPq) foi concebida como uma forma de incentivo aos pesquisadores detentores de título de doutorado e de destacada produção científica, para valorização de seu trabalho e dedicação frente a seus pares. Estas bolsas são altamente cobiçadas pelos pesquisadores de todas as áreas do conhecimento principalmente pelo status que conferem àqueles que as detêm, uma vez que diferencia o pesquisador dentre os demais. Desta forma, o perfil dos atuais bolsistas PQ se torna de interesse de toda comunidade científica.

As primeiras bolsas PQ na área de Química foram concedidas em 1976, e muitos dos pesquisadores contemplados naquela época ainda são produtivos e constam entre os atuais bolsistas PQ. Após várias alterações nos níveis e nos valores, as bolsas são atualmente divididas e hierarquizadas em 3 categorias: Sênior (PQ-SR), PQ-1 (sendo a categoria 1 subdividida nos níveis $1 \mathrm{~A}, 1 \mathrm{~B}, 1 \mathrm{C}$ e $1 \mathrm{D}$ ) e PQ-2. A bolsa PQ-Sênior, criada em 2007, é a mais recente categoria PQ do $\mathrm{CNPq}$, sendo a única que não concorre na demanda de julgamento de bolsas, pois é concedida pelo Conselho Deliberativo do CNPq, em caráter vitalício, a pedido do pesquisador que se manteve nos níveis 1A ou 1B por, no mínimo, 15 anos ininterruptos.

Este trabalho tem por objetivo informar à comunidade científica e às agências de fomento sobre o perfil dos bolsistas PQ da Química e assim contribuir para a análise da atual distribuição das bolsas. Este estudo faz uma análise do perfil dos 604 bolsistas PQ do Programa Básico de Química do CNPq com bolsa vigente em março de 2009, com base nas informações da Plataforma Lattes. Neste artigo é possível ter uma visualização do perfil dos pesquisadores das três categorias de bolsa concedidas pelo CNPq, sua distribuição geográfica, por instituições acadêmicas, por gênero, por idade científica e por áreas (analítica, físico-química, inorgânica e orgânica). O panorama atual do perfil dos pesquisadores contemplados com a bolsa de produtividade leva em conta, também, os índices numéricos de produtividade extraídos dos currículos Lattes destes pesquisadores, tais como fator de orientação, índice $\mathrm{H}$, número de artigos e somatório dos impactos. Tais fatores numéricos fazem parte dos critérios utilizados pelo Comitê Assessor de Química (CA-QU) desde 2006 e vigentes até 2011, conforme pode ser verificado no sítio do CNPq. ${ }^{1}$

*e-mail: ncsantos@cnpq.br

${ }^{\#}$ Grupos de Pesquisa em Radicais de Oxigênio- IB, UnB, Brasília, Brasil
Há uma série de questionamentos quanto aos índices bibliométricos e sua aceitação como determinantes da qualidade científica. No editorial de outubro de 2008 da Revista Science, intitulado "The Misused Impact Factor", Kai Simons, Presidente da European Life Scientist Organization e pesquisador do Max Planck Institute of Molecular Cell Biology and Genetics, argumenta que a qualidade dos artigos deve ser avaliada para determinar não somente sua contribuição para a ciência, mas também para ajudar as agências de financiamento a tomar decisões. ${ }^{2}$ Entretanto, na opinião do autor, não há atalhos numéricos para se avaliar qualidade individual em pesquisa. Ele destaca inconsistências em alguns dos mais importantes índices como o fator de impacto e afirma que o problema está no fato de que os jornais podem manipular o fator de impacto, dentre outras formas, aumentando o número de artigos de revisão, que são muito mais citados que os artigos primários. Esta opinião é compartilhada por cientometristas, inclusive o próprio criador do fator de Impacto, Eugene Garfield. ${ }^{3}$ Ele admite que o fator de impacto apresenta várias falhas e também particularidades para cada subárea de conhecimento e alerta para o perigo de se avaliar indivíduos usando o fator de impacto como critério, mas conclui que apesar de não ser uma ferramenta perfeita para se medir qualidade de artigos, o fator de impacto é uma das melhores que se dispõe.

O problema é que o fator de impacto é um indicador baseado no número de citações e o número de citações é um valor numérico objetivo baseado num método de seleção não-objetivo. ${ }^{4}$ Segundo Eduardo Katchburian, as citações podem ocorrer por cortesia entre os pares e há também a tendência de citar apenas revistas de maior prestígio. Esta discussão não é nova e já foi debatida no final da década passada nesta mesma revista, pelos Profs. Ângelo da Cunha Pinto e Jailson Bittencourt de Andrade que discutiram em seu artigo as limitações e riscos do uso do fator de impacto. ${ }^{5}$

Em 2005 foi criado por Hirsch o índice H que é aclamado por alguns como o melhor dentre os sistemas numéricos de qualificação da pesquisa. ${ }^{6}$ No entanto, é difícil acreditar que uma fórmula ou coeficiente possa contemplar todas as variáveis e complexidades envolvidas na pesquisa científica, principalmente por este índice estar diretamente baseado em citações e este ser um critério extremamente subjetivo. ${ }^{7,8}$ Para Hirsch o índice $\mathrm{H}$ teria vantagens sobre outros indicadores de produtividade, tais como o número total de artigos, que mede produtividade mas não mede o impacto dos trabalhos publicados; o número total de citações, que mede o impacto dos trabalho mas pode ser inflado por artigos muito citados mas que 
eventualmente não são representativos da carreira do pesquisador se ele não for o autor principal; o número de citações por artigo, que penaliza a alta produtividade e favorece a baixa produtividade; o número de artigos significativos, que é difícil de se obter e pode randomicamente favorecer ou desfavorecer indivíduos e, o número de citações dos artigos mais significativos, que tem as mesmas desvantagens do item anterior. ${ }^{6}$

Alguns pesquisadores consideram também que o índice $\mathrm{H}$, assim como o fator de impacto, não deveria ser usado para comparar pesquisadores de diferentes áreas, pois há diferença nos valores médios desses índices entre as áreas e as subáreas. ${ }^{9}$

O CNPq, em 2005, após uma série de questionamentos da comunidade científica sobre em quais parâmetros se baseavam os comitês na classificação de pesquisadores, solicitou a todos os comitês de assessoramento que estabelecessem critérios de julgamento trienais. Estes critérios foram disponibilizados no sítio do $\mathrm{CNPq}$, de modo a tornarem mais transparentes e passíveis de acompanhamento as recomendações das bolsas. Desde então, há uma busca dos comitês em definir parâmetros numéricos e/ou qualitativos que melhor definam as diferenças entre as categorias/níveis de bolsas PQ.

Apesar das controvérsias existentes a respeito dos índices numéricos, os critérios atuais de concessão de bolsa PQ, determinados pelo Comitê Assessor de Química, se referem a estes índices como acessórios de balizamento de qualificação científica para priorização das propostas. O CA-QU destaca em seus critérios que observa nos julgamentos a produção científica, a formação de recursos humanos, a contribuição para a inovação, a coordenação ou participação em projetos de pesquisa, a participação em atividades editoriais e de gestão científica e a administração de instituições e núcleos de excelência científica e tecnológica. Considera, também a perspectiva de futuro da atividade científica e tecnológica, evidenciada pela originalidade, relevância, exequibilidade e consistência do projeto, este último critério é mais relevante para os jovens pesquisadores da categoria 2.

\section{MÉTODOS}

A geração dos dados de produção científica para a realização deste trabalho seguiu os critérios pré-estabelecidos para o julgamento de propostas dentro do CNPq. O universo abordado foi definido como todos os pesquisadores ativos no $\mathrm{CNPq}$ do programa básico de Química no momento da geração das planilhas. Foram geradas seis planilhas distintas distribuídas entre dados dos pesquisadores e dados da produção científica cadastrados no Currículo Lattes do CNPq. As informações geradas foram extraídas da base de produção on-line do $\mathrm{CNPq}$, ou seja, refletem exatamente os dados cadastrados no momento da geração das mesmas, sendo que as informações sobre a produção científica se referem aos 5 últimos anos de produção (2004-fevereiro de 2009), baseado no ano da produção científica informado no Currículo Lattes. Esses dados estão disponíveis nos currículos de cada um dos pesquisadores para acesso público.

As informações da planilha de Pesquisadores Ativos foram extraídas, entre 4 e 10/2/09, da base de produção do CNPq selecionando todos os bolsistas ativos (em folha de pagamento) da modalidade PQ vinculados ao "Programa Básico de Química". Os dados presentes nesta seleção foram utilizados como base para a extração dos demais dados relativos à produção científica dos mesmos. A planilha de Artigos Completos Publicados em Periódicos teve seus dados extraídos da base de produção científica do Currículo Lattes no CNPq. Foi utilizado um algoritmo para localização e comparação por similaridade (Trigrama) dos nomes dos periódicos cuja informação do ISSN não estava presente ou estava incoerente no momento da busca dos dados. Este procedimento foi necessário para identificar todos os periódicos cadastrados para os pesquisadores e efetivar suas ligações, por meio do ISSN, com as tabelas de pontuação do JCR 2008 (Journal Citation Report). Foram realizadas criteriosa análise e correção de possíveis erros de digitação que impediam a atribuição automática dos respectivos valores do fator de impacto. As demais planilhas de produção científica dos pesquisadores foram extraídas diretamente da base do Currículo Lattes, sem necessidade de transformações ou ajustes.

A análise das datas de atualização desses currículos mostrou que mais de $82,5 \%$ dos currículos que fizeram parte do estudo haviam sido atualizados há menos de 3 meses e apenas 1,0\% há mais de 9 meses da data de coleta dos dados. Este levantamento garante que os dados estavam atualizados. A análise de consistência dessas informações não foi realizada uma vez que, ao aceitar publicar seu conteúdo na Plataforma Lattes, o pesquisador se responsabiliza pela veracidade dessas informações.

A análise da demanda de solicitações de bolsa PQ no programa básico de química nos julgamento de 2006 a 2008 foi feita com base nos dados da Plataforma Carlos Chagas.

O índice de orientação foi calculado conforme os critérios estabelecidos pelo CA-QU, e quantifica o envolvimento com formação e qualificação de recursos humanos na graduação e pós-graduação, considerando-se apenas as orientações concluídas de alunos nos últimos 5 anos. Foram consideradas as orientações concluídas entre 01/01/04 e 10/02/09 (data de extração dos dados dos currículos). São atribuídos diferentes pesos na orientação de alunos de iniciação científica, mestrado e doutorado. A idade científica é definida como o número de anos posteriores à publicação do primeiro artigo em revista indexada ao ISI Web of Knowledge (ISI-WoK). ${ }^{6}$ A verificação da categoria administrativa das instituições foi pesquisada no sítio da CAPES.

Os dados populacionais foram obtidos no sítio do IBGE e representam a estimativas das populações residentes em $1^{\circ}$ de julho de 2009, segundo o Brasil, em grandes regiões e unidades da federação. ${ }^{10}$

\section{RESULTADOS E DISCUSSÃO}

Em março de 2009 os bolsistas PQ da Química eram ao todo 604, sendo 222 deles na categoria PQ-1, 376 na categoria PQ-2 e 6 na PQ-SR. O levantamento das regiões geográficas e unidades da federação em que estão localizadas as instituições de execução dos projetos (Tabela 1) mostra que o Sudeste é a região do Brasil com maior número de bolsistas de PQ em todas as categorias/níveis de bolsa. O Sudeste possui 63,7\% do total de bolsistas PQ, sendo 100\% dos PQ-SR, 70,5\% dos PQ-1A, 80,4\% dos PQ-1B, 72,4\% dos PQ$1 C, 66,2 \%$ dos PQ-1D e 58,5\% dos PQ-2 (dados não mostrados). São Paulo é a unidade da federação com maior número de bolsistas PQ, possuindo 41,2\% dos bolsistas, enquanto no Espírito Santo não há nenhum. A região com menor número de bolsistas $\mathrm{PQ}$ é a região Norte, que possui apenas 4 bolsistas, sendo todos eles da categoria 2 e concentrados apenas no Pará e Rondônia, o que corresponde a $0,66 \%$ do total de bolsistas. A ausência de bolsistas PQ verificada nos estados do Tocantins, Mato Grosso, Amazonas, Roraima e Acre poderia ser atribuída à distância dos grandes centros e à dificuldade de transporte de reagentes e equipamentos, no entanto, esta mesma justificativa não se aplica ao estado do Espírito Santo. O Sul e o Nordeste possuem bolsistas em todos os níveis das categorias 1 e 2 . Tem-se $17,9 \%$ do total de bolsistas PQ na região Sul sendo sua maior participação no nível 1D (22,6\%). No Nordeste encontram-se 14,24\% dos bolsistas e a maior participação se dá na categoria $2(17,6 \%)$. O Centro-Oeste, com 3,5\% do total, não possui bolsistas PQ-1A e sua maior participação é encontrada na categoria 2 (4,79\%).

Quando existem recursos dos Fundos Setoriais na distribuição das bolsas PQ é estipulada uma cota mínima de 30\% das bolsas para pesquisadores das regiões Norte, Nordeste e Centro-Oeste. Considerando 
Tabela 1. Bolsistas PQ nas unidades da federação e regiões geográficas do Brasil $(n=604)$

\begin{tabular}{|c|c|c|c|c|c|}
\hline REGIÃO & UF & número de bolsas PQ & $\%$ de bolsas no total & população & Bolsas PQ/milhão de habitantes \\
\hline \multirow[t]{8}{*}{ Brasil } & & 604 & 100 & 191.480 .630 & 3,15 \\
\hline & RO & 1 & 0,17 & 1.503 .928 & 0,66 \\
\hline & $\mathrm{AC}$ & 0 & 0,00 & 691.132 & 0,00 \\
\hline & $\mathrm{AM}$ & 0 & 0,00 & 3.393 .369 & 0,00 \\
\hline & $\mathrm{RR}$ & 0 & 0,00 & 421.499 & 0,00 \\
\hline & PA & 3 & 0,50 & 7.431 .020 & 0,40 \\
\hline & AP & 0 & 0,00 & 626.609 & 0,00 \\
\hline & TO & 0 & 0,00 & 1.292 .051 & 0,00 \\
\hline \multirow[t]{10}{*}{ Norte } & & 4 & 0,66 & 15.359 .608 & 0,26 \\
\hline & MA & 2 & 0,33 & 6.367 .138 & 0,31 \\
\hline & PI & 1 & 0,17 & 3.145 .325 & 0,32 \\
\hline & $\mathrm{CE}$ & 15 & 2,48 & 8.547 .809 & 1,75 \\
\hline & $\mathrm{RN}$ & 4 & 0,66 & 3.137 .541 & 1,27 \\
\hline & PB & 16 & 2,65 & 3.769 .977 & 4,24 \\
\hline & $\mathrm{PE}$ & 19 & 3,15 & 8.810 .256 & 2,16 \\
\hline & $\mathrm{AL}$ & 6 & 0,99 & 3.156 .108 & 1,90 \\
\hline & $\mathrm{SE}$ & 6 & 0,99 & 2.019 .679 & 2,97 \\
\hline & BA & 17 & 2,81 & 14.637 .364 & 1,16 \\
\hline \multirow[t]{5}{*}{ Nordeste } & & 86 & 14,24 & 53.591 .197 & 1,60 \\
\hline & MG & 62 & 10,27 & 20.033 .665 & 3,09 \\
\hline & ES & 0 & 0,00 & 3.487 .199 & 0,00 \\
\hline & RJ & 74 & 12,25 & 16.010 .429 & 4,62 \\
\hline & SP & 249 & 41,23 & 41.384 .039 & 6,02 \\
\hline \multirow[t]{4}{*}{ Sudeste } & & 385 & 63,74 & 80.915 .332 & 4,76 \\
\hline & PR & 27 & 4,47 & 10.686 .247 & 2,53 \\
\hline & $\mathrm{SC}$ & 25 & 4,14 & 6.118 .743 & 4,09 \\
\hline & $\mathrm{RS}$ & 56 & 9,27 & 10.914 .128 & 5,13 \\
\hline \multirow[t]{5}{*}{ Sul } & & 108 & 17,88 & 27.719 .118 & 3,90 \\
\hline & MS & 3 & 0,50 & 2.360 .498 & 1,27 \\
\hline & MT & 0 & 0,00 & 3.001 .692 & 0,00 \\
\hline & GO & 5 & 0,83 & 5.926 .300 & 0,84 \\
\hline & $\mathrm{DF}$ & 13 & 2,15 & 2.606 .885 & 4,99 \\
\hline Centro-Oeste & & 21 & 3,48 & 13.895 .375 & 1,51 \\
\hline
\end{tabular}

Fonte dos dados populacionais: IBGE/DPE/COPIS/GEADD, estimativa da população para julho de 2009.

a contribuição destas três regiões juntas, encontram-se 18,4\% do total de bolsas PQ que estão concentradas majoritariamente na categoria 2 .

A análise da razão de número de bolsistas PQ por habitantes revelou que a média nacional é de 3,15 bolsistas por milhão de habitantes. Seria correto supor então que, no momento, valores diferentes disso indicariam distribuição não proporcional das bolsas pelas regiões e/ou unidades da federação. As regiões Sul e Sudeste apresentam razão superior à média nacional, com valores, respectivamente, de 3,90 e 4,76. As outras três regiões do Brasil apresentam razões bem inferiores à média nacional. Para a região Norte a razão é de 0,26 , Centro-Oeste é de 1,51 e para o Nordeste é de 1,60.

Mesmo dentro das regiões há diferença na distribuição das bolsas entre os estados. Na região Norte nenhum estado apresenta razão acima de 1,00. Paradoxalmente, no Nordeste e Centro-Oeste, apesar das médias regionais serem inferiores à média nacional, duas unidades da federação possuem razão superior à média nacional: a Paraíba $(4,24)$ e o Distrito Federal $(4,99)$. Na região Sul, apenas o Paraná possui razão inferior à média nacional, tendo valor de 2,53. O Rio Grande do Sul é a unidade da federação com a segunda maior razão bolsista $\mathrm{PQ}$ /milhão de habitantes, com valor de 5,13. Com relação ao Sudeste, o Espírito Santo tem razão igual a zero, pois como já foi mencionado não possui nenhum bolsista, enquanto o estado de São Paulo possui a maior razão entre todas as unidades da federação, com valor de 6,02. Este valor é 90,7\% superior à média nacional.

A Figura 1 mostra a divisão das bolsas pelas áreas da química por categorias/níveis. Pode-se observar que a área com menor número de bolsistas PQ é a química inorgânica. A parcela de contribuição da inorgânica frente às outras áreas da química já foi menor, mas nos últimos anos cresceu até $17,7 \%$. A tendência de menor participação se repete em todos os níveis de bolsa da categoria 1 e também na categoria 2, mas é mais acentuada no nível PQ-1B (10,9\%). A única categoria na qual a química inorgânica não é minoria, é a PQ-SR, em que há apenas 6 bolsistas, distribuídos igualmente entre inorgânica, analítica e orgânica. A físico-química possui maior número no total de bolsas $(29,8 \%$ ) e mais de $30 \%$ dos bolsistas em cada nível da categoria 1. A química orgânica vem em segundo em número total de bolsistas (29,0\%) e em primeiro nos níveis PQ-1B (41,3\%) e PQ-1C(34,8\%). Em terceiro está a química analítica com $23,5 \%$ do total dos bolsistas tendo maior participação no nível PQ-1D (27,0\%).

Uma análise mais detalhada e por subárea (dado não mostrado) revela que a química de produtos naturais é a subárea com maior número de bolsistas PQ possuindo, sozinha, 10,3\% dos bolsistas (62), e sendo seguida pela síntese orgânica (53), pela análise de traço e a química ambiental (50) e pela química teórica (41). Juntas, essas 4 


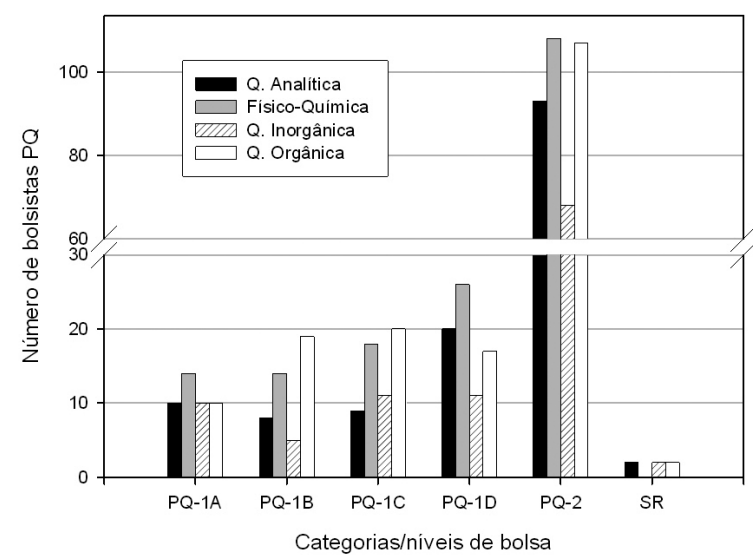

Figura 1. Número de bolsistas $P Q$ nas várias categorias de bolsa por área da química $(n=604)$

subáreas possuem $28 \%$ de todas as bolsas. Por outro lado, as subáreas de gravimetria, de química nuclear e radioquímica, de titrimetria e de evolução, sistemática e ecologia química possuem apenas 1 bolsista PQ cada $(0,17 \%)$.

A análise da demanda de solicitações de bolsa PQ no programa básico de química nos julgamentos de 2006 a 2008 mostrou que 15,2\% de todos os pedidos de bolsa $\mathrm{PQ}$ pertenciam à química inorgânica. A área com maior número de propostas foi a orgânica $(30,4 \%)$, seguida pela físico-química $(27,6 \%)$ e pela química analítica $(24,6 \%)$. Estas proporções nos pedidos de bolsa explicam ao menos em parte a divisão das bolsas pelas áreas da química observadas na Figura 1. Com relação às subáreas, a análise dos últimos 3 anos (2006-2008) mostrou que aquelas que possuem menos bolsistas PQ são também as que menos receberam propostas de bolsa. Outras subáreas cujas submissões estão comparativamente abaixo da média são a termodinâmica química, a fotoquímica inorgânica e não-metais e seus compostos, com menos de 4 pedidos de bolsa cada uma delas. A química nuclear e radioquímica, por exemplo, não recebe há 3 anos nenhum pedido de bolsa PQ.

A análise do número de bolsistas por gênero (Figura 2) mostra que as bolsistas do sexo feminino detêm $32,8 \%$ do total das bolsas $\mathrm{PQ}$ da química. Este valor é inferior à participação feminina no total de bolsas PQ concedidas a todas as grandes áreas de conhecimento que, em 2008, era de 33,8\%. ${ }^{11}$ A maior participação feminina se dá na categoria 2, na qual as mulheres correspondem a 40,2\% dos bolsistas. Nos níveis 1B, 1C e 1D os percentuais da participação feminina são de respectivamente 15,$2 ; 29,3$ e $25,7 \%$. A menor participação feminina é observada no nível 1A, em que apenas 4,8\% das bolsas pertencem a mulheres. O percentual feminino no nível $1 \mathrm{~A}$ da química é muito inferior ao observado no total geral de bolsas do CNPq que em 2008 era de $23,6 \% .^{11}$

Essa menor presença feminina nos níveis da categoria 1 tenderia a se amenizar com o tempo, já que a participação feminina na categoria 2 é mais elevada. No entanto, os números do ano de 1999 eram semelhantes aos de hoje e passados 10 anos o quadro não se alterou. Segundo Jaqueline Leta, "apesar do crescimento da participação de mulheres nas atividades de C\&T, as chances de sucesso e reconhecimento na carreira ainda são reduzidas". De acordo com a autora isso acontece, dentre outros motivos, porque o sistema é controlado predominantemente por homens e isso dificultaria a ascensão feminina aos níveis mais elevados. ${ }^{12}$ Apesar deste contexto, dentre os 6 bolsistas PQ-SR há duas mulheres que superaram as dificuldades de ascensão aos mais altos níveis e se mantiveram bolsistas PQ-1A por mais de 15 anos ininterruptos, são as Profas. Carol H. Collins e Blanka Wladislaw.

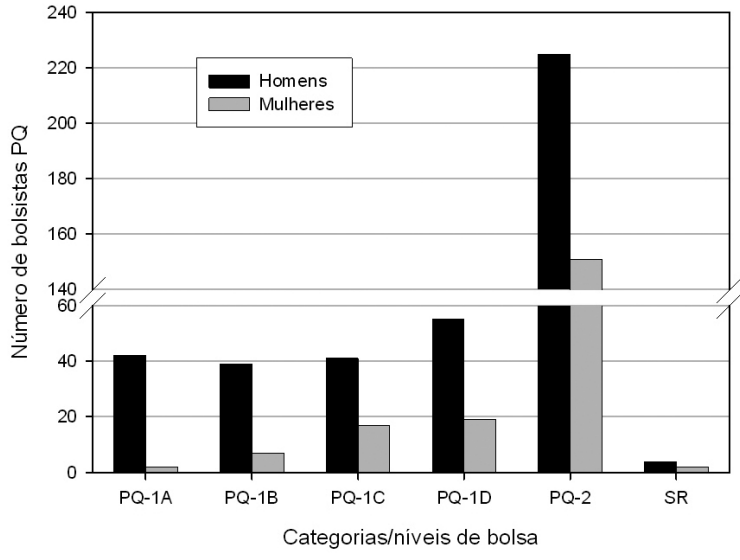

Figura 2. Número de bolsistas $P Q$ nos vários níveis/categorias de bolsa por gênero do bolsista $(n=604)$

A Tabela 2 apresenta o ranking das instituições que mais possuem bolsistas PQ em seus quadros. Destaca-se que as cinco primeiras colocadas são da região Sudeste e possuem, juntas, 45,9\% dos bolsistas PQ da química e mais da metade dos bolsistas PQ dos níveis 1A, 1B, 1C e 1D. Dentre todas as instituições, a USP é a primeira colocada, com 17,38\% dos bolsistas, e também possui o maior número de bolsistas em todas as categorias, exceto na sênior. A instituição melhor colocada da região Sul é a UFRGS que ocupa a $6^{\mathrm{a}}$ posição no ranking, com 31 bolsistas. A melhor colocada da região Nordeste é a UFPE, na $9^{\text {a }}$ posição, com 16 bolsistas. Na região Centro-Oeste, a UnB é a melhor colocada, ocupando a $11^{\text {a }}$ posição, com 13 bolsistas. Nenhuma instituição da região Norte figura dentre as 21 melhores classificadas. Dentre as 69 instituições que possuem bolsistas PQ, 1 instituição é municipal e possui 1 bolsista, 10 são instituições privadas com 17 bolsistas, 15 são instituições estaduais com 227 bolsistas e 43 são instituições federais com 359 bolsistas ao todo.

O levantamento dos dados referentes à conclusão do doutorado (dados não mostrados) revelou que 73,6\% dos bolsistas concluíram o doutorado em instituições brasileiras, sendo 67,5\% em instituições da região Sudeste. A instituição em que mais bolsistas PQ concluíram doutorado foi a USP, responsável por 29,0\% deles. Estes dados, comparados àqueles das Tabelas 1 e 2, demonstram uma forte tendência dos pesquisadores que concluíram seus doutorados no Sudeste em permanecerem nessa região.

A grande concentração de bolsistas PQ da categoria 1 e de grandes laboratórios nas instituições do Sudeste atrai os pesquisadores mais jovens que enxergam aí uma oportunidade de ascensão na carreira. Isto pode explicar parte dos 220 bolsistas da categoria 2 estabelecidos no Sudeste. Somado a isso tem-se o aporte de grandes recursos financeiros das FAP's estaduais (FAPESP, FAPEMIG, FAPERJ), enquanto nos outros estados as agências de fomentos são bem menos prósperas. Como destacou Otávio Carpinteiro em seu manifesto de 2008, esta situação desencoraja os pesquisadores de atuarem em pequenos centros de pesquisa, pois suas produções científicas não alcançariam, em tempo equivalente, o mesmo patamar das produções dos pesquisadores dos grandes centros. ${ }^{13}$

A Figura 3 mostra que não há homogeneidade nos níveis de bolsa no que se refere ao índice $\mathrm{H}$, mesmo quando os valores são analisados em função das áreas de conhecimento da química às quais pertencem os bolsistas. Ainda assim, quando calculadas as médias por nível/ categoria, verifica-se queda dos valores do maior nível para o menor. A média do índice $\mathrm{H}$ dos pesquisadores do nível $1 \mathrm{~A}$ é de $24,0 \pm 7,1$; no nível $1 \mathrm{~B}$ é de $17,4 \pm 4,1$; para $1 \mathrm{C}$ é de $13,5 \pm 2,5$ e para os PQ-1D é de $12,3 \pm 2,5$. Dentre todos os bolsistas PQ, o maior índice $\mathrm{H}$ é de um pesquisador da química analítica, com índice $\mathrm{H}$ igual a 47. Para 
Tabela 2. Ranking das 21 Instituições com maior número de bolsistas PQ de química por nível/categoria de bolsa

\begin{tabular}{|c|c|c|c|c|c|c|c|c|c|c|c|}
\hline \multirow[t]{2}{*}{ Instituição } & \multirow{2}{*}{$\begin{array}{c}\text { Posição no } \\
\text { Ranking }\end{array}$} & \multirow{2}{*}{$\begin{array}{l}\text { Número de } \\
\text { bolsistas }\end{array}$} & \multirow{2}{*}{$\begin{array}{c}\% \text { de bolsas } \\
\text { no total }\end{array}$} & \multicolumn{6}{|c|}{ Categorias/Níveis de bolsa } & \multirow[t]{2}{*}{ UF } & \multirow{2}{*}{$\begin{array}{c}\text { Categoria } \\
\text { Administrativa }\end{array}$} \\
\hline & & & & $1 \mathrm{~A}$ & $1 \mathrm{~B}$ & $1 \mathrm{C}$ & $1 \mathrm{D}$ & 2 & SR & & \\
\hline USP & $1^{\circ}$ & 105 & 17,38 & 15 & 13 & 11 & 20 & 45 & 1 & SP & Estadual \\
\hline UNICAMP & $2^{\circ}$ & 55 & 9,11 & 9 & 7 & 9 & 6 & 21 & 3 & SP & Estadual \\
\hline UFRJ & $3^{\circ}$ & 41 & 6,79 & 3 & 3 & 5 & 5 & 24 & 1 & RJ & Federal \\
\hline UNESP & $4^{\circ}$ & 39 & 6,46 & 1 & 3 & 4 & 6 & 25 & & SP & Estadual \\
\hline UFMG & $5^{\circ}$ & 37 & 6,13 & 1 & 1 & 2 & 6 & 27 & & MG & Federal \\
\hline UFRGS & $6^{\circ}$ & 31 & 5,13 & 2 & & 5 & 8 & 16 & & RS & Federal \\
\hline UFSCAR & $7^{\circ}$ & 25 & 4,14 & & 9 & 2 & 2 & 12 & & SP & Federal \\
\hline $\begin{array}{l}\text { UFSC } \\
\text { UFSM }\end{array}$ & $8^{\circ}$ & 21 & 3,48 & $\begin{array}{l}4 \\
2\end{array}$ & $\begin{array}{l}1 \\
4\end{array}$ & $\begin{array}{l}1 \\
2\end{array}$ & $\begin{array}{l}1 \\
4\end{array}$ & $\begin{array}{c}14 \\
9\end{array}$ & & $\begin{array}{l}\mathrm{SC} \\
\mathrm{RS}\end{array}$ & $\begin{array}{l}\text { Federal } \\
\text { Federal }\end{array}$ \\
\hline UFPE & $9^{\circ}$ & 16 & 2,65 & 2 & 1 & 2 & 2 & 9 & & PE & Federal \\
\hline $\begin{array}{l}\text { UFBA } \\
\text { UFC } \\
\text { UFPR }\end{array}$ & $10^{\circ}$ & 14 & 2,32 & 2 & 1 & $\begin{array}{l}1 \\
1 \\
2\end{array}$ & 3 & $\begin{array}{c}11 \\
12 \\
9\end{array}$ & & $\begin{array}{l}\text { BA } \\
\text { CE } \\
\text { PR }\end{array}$ & $\begin{array}{l}\text { Federal } \\
\text { Federal } \\
\text { Federal }\end{array}$ \\
\hline UFPB & $11^{\circ}$ & 13 & 2,15 & 1 & 1 & & & 11 & & PB & Federal \\
\hline UnB & & & & & 1 & 1 & 1 & 10 & & $\mathrm{DF}$ & Federal \\
\hline UFF & $12^{\circ}$ & 12 & 1,99 & 1 & 1 & 2 & & 8 & & $\mathrm{RJ}$ & Federal \\
\hline UFJF & $13^{\circ}$ & 7 & 1,16 & & & 1 & 1 & 5 & & $\mathrm{RJ}$ & Federal \\
\hline $\begin{array}{l}\text { UERJ } \\
\text { UEM } \\
\text { UFAL } \\
\text { UFS } \\
\end{array}$ & $14^{\mathrm{o}}$ & 6 & 0,99 & 1 & & 1 & $\begin{array}{l}2 \\
1 \\
\end{array}$ & $\begin{array}{l}5 \\
5 \\
4 \\
5\end{array}$ & & $\begin{array}{l}\text { RJ } \\
\text { PR } \\
\text { AL } \\
\text { SE } \\
\end{array}$ & $\begin{array}{c}\text { Estadual } \\
\text { Estadual } \\
\text { Federal } \\
\text { Federal }\end{array}$ \\
\hline
\end{tabular}

O ranking foi estabelecido em função do número de bolsistas PQ na instituição, a ordem de aparecimento das instituições de mesma classificação na tabela levou em conta a categoria/nível dos bolsistas. A categoria administrativa das instituições foi pesquisada no sítio da CAPES.

os PQ-SR o valor médio encontrado foi de $17,5 \pm 5,9$, mas para os pesquisadores mais antigos é muito difícil calcular o índice $\mathrm{H}$ com exatidão, pois os artigos começaram a ser indexados ao ISI-WoK apenas a partir de 1955, o primeiro ano do banco de dados.

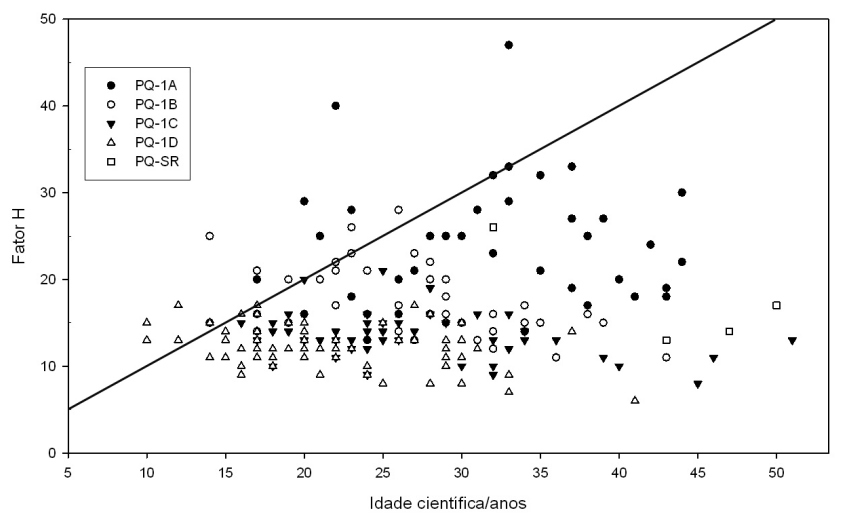

Figura 3. Fator H dos bolsistas em Produtividade em Pesquisa das categorias $P Q-1$ e PQ-SR com o avanço da idade científica $(n=211)$. Valores de índice $H$ calculados pelos próprios pesquisadores e informados em seus currículos na Plataforma Lattes (extração dos dados em fevereiro de 2009)

Apesar de o índice H não ser considerado pelo CA-QU para classificação na categoria 2 , há nessa categoria mais de uma centena de pesquisadores com índice $\mathrm{H}$ igual ou maior que 10 , com destaque para um pesquisador da inorgânica com índice $H$ igual a 21. Isto demonstra que ao menos neste quesito há uma grande pressão dos pesquisadores da categoria 2 para ascenderem aos níveis da categoria 1. Ao mesmo tempo, é possível encontrar nos níveis IC e ID pesquisadores com índice $\mathrm{H}$ menor que 10 . No entanto, deve-se observar a que subárea estes pesquisadores pertencem, pois, como destacou o próprio Hirsch, há diferenças entre os índices H típicos para cada área de conhecimento.

Observou-se que as médias dos índices $\mathrm{H}$ dos bolsistas da química analítica e físico-química são ligeiramente superiores às médias de cada nível da categoria 1. Em 3 dos 4 níveis da categoria 1, a química orgânica apresenta os menores valores médios de $\mathrm{H}$.

No mesmo artigo em que Hirsch introduziu o conceito do índice $\mathrm{H}$, apresentou também o índice m, que não é utilizado pelo CA-QU. Segundo ele, o índice $\mathrm{m}\left(\mathrm{m}=\mathrm{H} / \mathrm{t}_{\text {pub }}\right)$ avalia o sucesso da carreira científica do pesquisador pelo tempo transcorrido desde a publicação de seu primeiro artigo científico $\left(\mathrm{t}_{\text {pub }}\right.$ ). Para Hirsch, um índice $\mathrm{m} \sim 1$ caracteriza um pesquisador bem sucedido. Índices $\mathrm{m} \sim 2$ caracterizam pesquisadores fora do comum, encontrados apenas nas melhores universidades, e índice $\mathrm{m} \sim 3$ ou maiores caracterizam indivíduos realmente únicos.

Nessas considerações, assim como nas do índice $\mathrm{H}$, deve-se levar em conta a área e a subárea de atuação do pesquisador, pois, como já mencionado, há diferenças entre os ritmos de crescimento do índice $\mathrm{H}$ de pesquisadores de diferentes áreas. A reta diagonal nesta mesma figura representa índice $m=1$ e observa-se que a maioria dos pesquisadores da categoria 1 e da categoria sênior encontra-se abaixo da linha de $\mathrm{m}=1$, ou seja, na qual $\mathrm{t}_{\text {pub }}=\mathrm{H}$. Dentre os bolsistas PQ da categoria 1 da química, 20 possuem índice m maior que 1,00 e 29 possuem índice m entre 1,00 e 0,80 . O maior valor de m é de 1,82 , de um pesquisador do nível 1A da físico-química. Os valores médios de m para os níveis da categoria 1 mostram que há sobreposição entre os grupos no que se refere aos valores de m: PQ-1A (0,80 $\pm 0,31)$; PQ-1B $(0,70 \pm 0,31)$; $\mathrm{PQ}-1 \mathrm{C}(0,55 \pm 0,18)$ e PQ-1D $(0,65 \pm 0,30)$. Uma ressalva que deve ser feita é a de que os valores descritos por Hirsch para o índice $m$ levam em conta os valores médios do índice $\mathrm{H}$ observados nos países desenvolvidos, nos quais o número de publicações é muitíssimo mais elevado do que no Brasil, ${ }^{14}$ o que eleva os valores dos índices $\mathrm{H}$ e m a valores atípicos para países em desenvolvimento. 
A Figura 4 mostra a distribuição dos bolsistas em relação ao somatório do fator de impacto das revistas onde foram publicados os artigos do pesquisador nos últimos 5 anos versus o número de artigos publicados. Em média os bolsistas 1A publicaram 44,9 artigos cada nos últimos 5 anos, enquanto os níveis $1 \mathrm{~B}, 1 \mathrm{C}$ e $1 \mathrm{D}$ tiveram médias de 41,6; 34,3 e 28,2 artigos publicados, respectivamente. Os bolsistas da categoria sênior mostraram que continuam ativos e publicaram 39,8 artigos em média, enquanto os bolsistas da categoria 2 publicaram cada um 20,9 artigos, em média. Apesar de no geral os bolsistas da categoria 1 terem mais artigos publicados que os da categoria 2 , podese observar casos fora do comum em todos os níveis/categorias como, por exemplo, o do pesquisador da categoria 2 da química inorgânica que publicou nos últimos 5 anos 177 artigos.

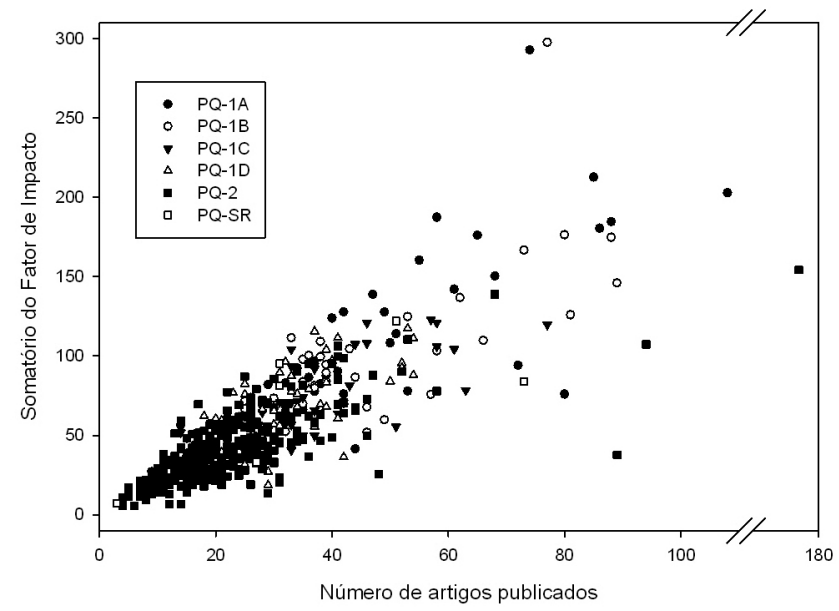

Figura 4. Somatório do fator de impacto dos bolsistas em Produtividade em Pesquisa pelo número de artigos publicados. O somatório do fator de impacto das revistas foi calculado considerando-se apenas os artigos publicados entre 2004-2009 (extração dos dados em fevereiro de 2009) $(n=601)$

Com relação ao somatório do fator de impacto observa-se também que os níveis mais elevados de bolsa possuem valores médios maiores: 1A $(99,2) ; 1 \mathrm{~B}(85,4) ; 1 \mathrm{C}(63,8) ; 1 \mathrm{D}(55,7)$; categoria $2(36,7) \mathrm{e}$ sênior $(67,6)$. O maior valor observado foi o de um pesquisador do nível 1B da química orgânica, cujo somatório do fator de impacto foi de 285,0 , enquanto o menor valor foi de 5,56 , de um pesquisador da categoria 2. Como mencionado anteriormente, as revistas das diferentes áreas e subáreas possuem fatores de impacto característicos e a comparação de pesquisadores com relação a esse critério deve levar em conta essas particularidades.

A Figura 5 apresenta a relação do índice de orientação (IO) com o tempo transcorrido após a conclusão do doutorado, e demonstra que a maioria dos pesquisadores possui um maior envolvimento na formação de recursos humanos no período de 10 aos 30 anos. Observa-se uma grande dedicação à orientação de alunos independente da categoria/ nível de bolsa. Após os 40 anos de conclusão do doutorado observa-se um decaimento nos índices de orientação, provavelmente relacionado à aposentadoria e afastamento das atividades de orientação. O pesquisador que mais orientou nos últimos 5 anos foi o recentemente falecido Prof. Octávio Ceva Antunes, que à época da coleta dos dados tinha bolsa PQ-1C, e seu índice de orientação era de 89,25. A média do índice de orientação, nos últimos 5 anos, dos pesquisadores por nível é a seguinte: PQ-SR $(16,8)$, PQ-1A $(23,8)$, PQ-1B (23,2), PQ-1C (19,10), PQ-1D (17,30) e PQ-2 (11,37). Há, no entanto, uma grande dispersão dos valores de $\mathrm{IO}$ em relação às médias, levando a valores de desvio padrão relativo superiores a $48 \%$ em todos os níveis/categorias.

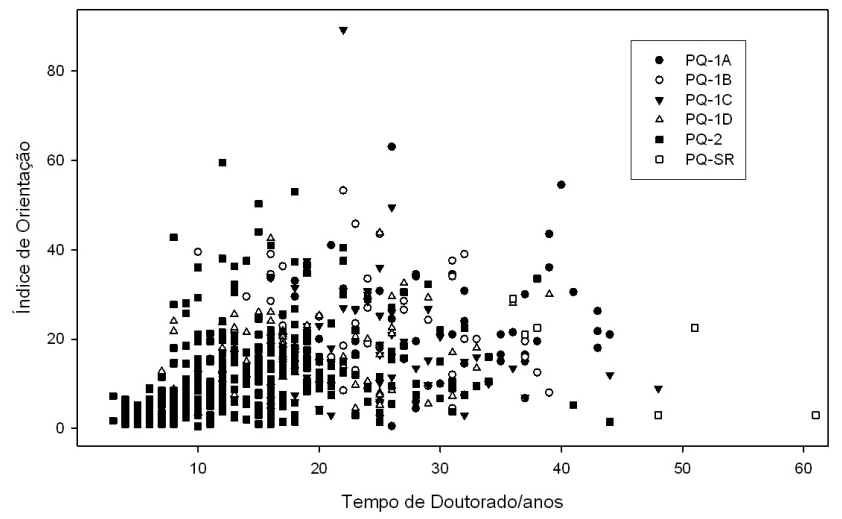

Figura 5. Índice de orientação dos bolsistas em Produtividade em Pesquisa pelo tempo transcorrido desde a conclusão do doutorado em anos. O Índice de Orientação levou em conta apenas as orientações concluídas entre 20042009 (extração dos dados em fevereiro de 2009) $(n=604)$

\section{CONCLUSÃO}

É perceptível a concentração de bolsistas PQ na região Sudeste e a pequena presença deles na região Norte, fator muito relacionado à infraestrutura disponível nas instituições acadêmicas e de pesquisa da última região. Ainda que os Fundos Setoriais determinem que $30 \%$ de seus recursos sejam destinados às regiões Norte, Nordeste e Centro-Oeste, estes recursos não são equivalentemente distribuídos entre as três regiões. Estes recursos são também insuficientes para compensar a forte atração que os grandes centros de pesquisa exercem sobre os pesquisadores, dificultando um crescimento mais acentuado nas regiões Norte e Centro-Oeste. A análise do número de bolsistas PQ por estado isoladamente pode levar a uma interpretação equivocada da distribuição de bolsistas, mas se considerarmos a razão do número de bolsista $\mathrm{PQ}$ por milhão de habitantes evidenciase que, mesmo quando considerada a densidade demográfica da população brasileira, há concentração acentuada de bolsistas no Sul e Sudeste.

O estado de São Paulo lidera o ranking das unidades da federação com maior número de bolsistas, sendo que USP e UNICAMP juntas possuem mais de um terço de todos os bolsistas e mais da metade dos bolsistas do nível 1A.

A grande maioria dos bolsistas PQ da química é do sexo masculino $(67,2 \%)$, principalmente nos níveis da categoria 1 , nos quais a participação feminina é ainda mais reduzida. Em 2001 apenas 29\% dos pesquisadores com bolsa de produtividade da química eram do sexo feminino e nenhum dos membros do Comitê Assessor de Química do CNPq eram mulheres. Hoje essa situação se modificou um pouco, já que o percentual de mulheres bolsistas PQ subiu para $32,8 \%$, e entre os 12 membros titulares e suplentes do CA-QU estão presentes 2 mulheres. Isto indica um aumento da influência feminina em pontos de decisão, mas não descarta a limitação na ascensão feminina, como afirmou Thereza Amélia Soares. ${ }^{15}$

A distribuição das bolsas PQ pelas 4 áreas da química não é equitativa, o que pode estar relacionado com a maior demanda de pesquisadores nas áreas de físico-química e orgânica. Quanto às subáreas, não é de se estranhar que algumas possuam apenas um bolsista, enquanto outras possuem dezenas deles, pois a demanda é bem discrepante entre as subáreas. Uma explicação para isso pode estar relacionada à dinâmica de evolução da própria química, que com o passar do tempo privilegia determinadas subáreas em detrimento de outras, como é o caso das técnicas clássicas de volumetria e gravimetria que são cada vez menos utilizadas e têm sido substituídas por técnicas analíticas mais sensíveis e precisas. ${ }^{16}$ 
Não foi observada homogeneidade no perfil dos bolsistas dentro de um mesmo nível/categoria, no que se refere aos índices numéricos utilizados pelo Comitê Assessor de Química (índice H, somatório do JCR e índice de orientação nos últimos 5 anos). Apesar dos esforços do $\mathrm{CNPq}$ e do CA-QU em tornar a distribuição das bolsas mais transparente e passível de acompanhamento, com o estabelecimento de parâmetros numéricos e/ou qualitativos que melhor definam as diferenças entre as categorias/níveis de bolsas PQ, essas diferenças ainda não são evidentes.

De 2002 a 2008 o número total de bolsas PQ aumentou de 7.765 a $10.031(29,2 \%)$, sendo que o investimento em bolsas PQ em 2008 foi de 192,6 milhões de reais. ${ }^{17}$ Em 2009 o número de bolsas e o investimento voltaram a aumentar, e já há sinalização de que em 2010 esses números aumentarão ainda mais. Neste contexto, a distribuição das bolsas PQ da química e das demais grandes áreas se torna cada vez mais estratégica, e zelar pela boa aplicação desses recursos é um dever de toda sociedade. Assim, é de suma importância a divulgação do perfil dos atuais bolsistas em Produtividade em Pesquisa da Química e este estudo contribui para a avaliação da distribuição das bolsas e contextualização dos pesquisadores dentre os que são hoje considerados a elite da química no país.

\section{AGRADECIMENTOS}

AoConselho Nacional de Desenvolvimento Científico e Tecnológico (CNPq/Brazil), à designer J. Ferreira pelo tratamento das figuras e àqueles que contribuíram com valiosas sugestões e críticas: P. S. Morales, C. D’Almeida, T. M. Scherrer, S. T. Ferreira, M. HermesLima, E. J. F. Santos e A. M. da C. Carvalho.

\section{GLOSSÁRIO}

Índice de orientação (IO): é calculado pelo somatório do número de alunos de cada modalidade de orientação multiplicado por seus respectivos pesos: iniciação científica $(0,5)$, mestrado $(1,5)$ e doutorado (3,0). Às co-orientações são atribuídos pesos na metade do valor das orientações como orientador principal. ${ }^{1}$

Fator de impacto: calculado pela razão número de citações nos últimos 2 anos/número de artigos publicados pelo periódico nos mesmos 2 anos. $^{3}$

Índice $\mathrm{H}$ : um pesquisador tem índice $\mathrm{h}$ quando possui ao menos h artigos com no mínimo h citações cada, e os outros artigos possuem menos que $\mathrm{h}$ citações. ${ }^{6}$

Índice m: é calculado pela razão índice h/idade científica em anos. ${ }^{6}$

Idade científica: número de anos decorridos desde o ano de publicação do primeiro artigo em revista indexada. ${ }^{6}$
Áreas e subáreas da química conforme distribuição no banco de dados do CNPq:

Físico-química: cinética química e catálise; eletroquímica, espectroscopia; química nuclear e radioquímica; química teórica; química de interfaces; química do estado condensado; termodinâmica química.

Química Analítica: análise de traços e química ambiental; eletroanalítica; gravimetria; instrumentação analítica; métodos óticos de análise; separação; titimetria.

Química Inorgânica: compostos de coordenação; compostos organometálicos; determinação de estrutura de compostos inorgânicos; fotoquímica inorgânica; físico-química inorgânica; não-metais e seus compostos; química bio-inorgânica.

Química Orgânica: estrutura, conformação e estereoquímica; evolução, sistemática e ecologia química; físico-química orgânica; fotoquímica orgânica; polímeros e coloides; química dos produtos naturais; síntese orgânica.

\section{REFERENCIAS}

1. http://www.cnpq.br/cas/ca-qu.htm\#criterios, acessada em Outubro 2009.

2. Simons, K.; Science 2008, 322, 165.

3. Garfield, E.; J. Am. Med. Assoc. 2006, 295, 90.

4. Katchburian, E.; Sao Paulo Medical Journal 2008, 126, 202.

5. Pinto, A. C.; de Andrade, J. B.; Quim. Nova 1999, 22, 448

6. Hirsch, J. E.; Proc. Natl. Acad. Sci. 2005, 102, 16569.

7. Hermes-Lima, M.; Alencastro, A. C. R.; Santos, N. C. F.; Navas, C. A.; Beleboni, R. O.; Comp. Biochem. Physiol., Part C: Toxicol. Pharmacol. 2007, 146, 1 .

8. Cho, A.; ScienceNOW 2005, 812, 1.

9. Kelly, C. D.; Jennions, M. D.; Trends in Ecology \& Evolution 2006, 21, 167.

10. http://www.ibge.gov.br/home/estatistica/populacao/estimativa2009/ estimativa.shtm, acessada em Outubro 2009.

11. http://www.cnpq.br/estatisticas/TabelasdeQuantitativos/292_SexoPQ_ CatNivel_0108_n.xls acessada em Outubro 2009.

12. Leta, J.; Estudos Avançados 2003, 17, 271.

13. Carpinteiro, O. A. S.; Jornal da Ciência, e-mail 3450, edição de 15/2/2008.

14. Hermes-Lima, M.; Santos, N. C. F.; Alencastro, A. C. R.; Ferreira, S. T.; IUBMB Life 2007, 59, 199.

15. Soares, T. A.; Quim. Nova 2001, 24, 281.

16. Brett, C. M. A.; Química 2006, 100, 31.

17. http://www.cnpq.br/estatisticas/bolsas/modalidade.htm, acessada em Outubro 2009. 